\title{
Cobalt (II)-Mediated Molecularly Imprinted Polymer as a Monolithic Stationary Phase for Separation of Racemic Citronellal by Liquid Chromatography
}

\author{
Suci Amalia (D), ${ }^{1,2}$ Nilna Assasiatur Rafika, ${ }^{2}$ Shova Audinia Hardiyanti, ${ }^{1,2}$ Adi Dwi Ashari, ${ }^{1}$ \\ Bhisma Wildan Khabibi, ${ }^{1}$ Elvina Dhiaul Iftitah, ${ }^{1}$ Warsito Warsito, ${ }^{1}$ Aliya Nur Hasanah $\mathbb{D}{ }^{3}$ \\ and Akhmad Sabarudin (iD) \\ ${ }^{1}$ Department of Chemistry, Faculty of Science, Brawijaya University, Malang 65145, Indonesia \\ ${ }^{2}$ Department of Chemistry, Faculty of Science and Technology, Islamic State University Maulana Malik Ibrahim, \\ Malang 65144, Indonesia \\ ${ }^{3}$ Pharmaceutical Analysis and Medicinal Chemistry Department, Faculty of Pharmacy, Universitas Padjadjaran, \\ Sumedang 45363, Indonesia \\ ${ }^{4}$ Research Center for Advanced System and Material Technology (ASMAT), Brawijaya University, Malang 65145, Indonesia \\ Correspondence should be addressed to Akhmad Sabarudin; sabarjpn@ub.ac.id
}

Received 8 April 2021; Revised 10 January 2022; Accepted 31 January 2022; Published 28 February 2022

Academic Editor: Vera R. Constantino

Copyright (C) 2022 Suci Amalia et al. This is an open access article distributed under the Creative Commons Attribution License, which permits unrestricted use, distribution, and reproduction in any medium, provided the original work is properly cited.

\begin{abstract}
A metal-mediated molecularly imprinted polymer (MMIP) monolithic column was prepared as the stationary phase for highperformance liquid chromatography (HPLC) and applied to the enantiomeric separation of rac-citronellal. MMIP column was prepared through in situ copolymerizations with the ionic liquid 1-butyl-3-methylimidazolium tetrafluoroborate/[BMIM][BF $\left.{ }_{4}\right]$ as the primary pore-forming agent and cobalt(II) acetate as the metal pivot. Interactions between polymer components in the synthesized monolith were assessed by FTIR to identify the functional groups. The monolith morphology was characterized with SEM, and the template removal was detected by UV Spectrophotometry at $253 \mathrm{~nm}$. In this study, (R)-(+)-citronellal was used as a template, whereas 4-vinylpyridine (4-VP) was employed as the functional monomer with two monomer crosslinkers, trimethylolpropane trimethacrylate (TRIM), and ethylene glycol dimethacrylate (EDMA). The ternary mixture of porogenic solvent consisted of $[\mathrm{BMIM}]\left[\mathrm{BF}_{4}\right]$, dimethylformamide (DMF), and dimethyl sulfoxide (DMSO) with the applied ratio of $1: 1: 1$ (v/v) and $10: 1: 5(\mathrm{v} / \mathrm{v})$ for the preparation of MMIP using TRIM and EDMA crosslinkers, respectively. Co(II) ion was added to the porogenic solvent before being mixed with the functional monomer and the crosslinker mixtures. Separating the rac-citronellal was achieved on the synthesized MMIP, showing better selectivity than the monolithic metal-mediated nonimprinted polymer (MNIP), nonimprinted polymer (NIP), and molecularly imprinted polymer (MIP).
\end{abstract}

\section{Introduction}

Monoliths have an excellent ability to separate isomers, especially as chiral stationary phase (CSP) in high-performance liquid chromatography (HPLC). They have porous structures with sizes between micro and macro; thus, they may provide good pressure reduction and increase the mass transfer kinetics facilitating higher flow rates $[1,2]$.
Additionally, monolith materials could also reduce the length of the diffusion path while providing flow resistance [3-5].

Molecularly imprinted polymer (MIP), as one of the techniques for the synthesis of stationary phases for chromatography, is increasingly in demand for separating enantiomer compounds [6-9]. The stationary phase is prepared by a hollow polymer formation after template 
removal from the polymer structure. Accordingly, such a technique offers high selectivity due to the hollow parts that will recognize molecules in the shape and size of the template $[10,11]$. MIP is further developed by adding metal ions into the solution mixture, acting as a bridge between the functional monomer and the template via coordinate bonding. Using metal pivot will keep the monomer in the template vicinity by preventing the free motion of functional groups involved in the reaction, by decreasing nonspecific binding sites, and by increasing selectivity towards analytes [12, 13]. This later technique is called a metal-mediated imprinted polymer (MMIP).

Metal ions including Co (II), Cu (II), Zn (II), and Ni (II) have been recognized for their use in MMIP preparation applied to the separation of racemic mandelic acids [10]. Sun et al. [14] demonstrated that $\mathrm{Zn}$ (II), implemented as a metal center in the extraction of chicoric acid from the roots of Cichorium intybus L., could be used to overcome a weak hydrogen bond between the template and functional monomer. A longer retention time is required to obtain chicoric acid than its analogs. Moreover, the purification of methyl gallate was carried out with MIP, as reported by Zhong et al. [15]. It was found that adding a template and $\mathrm{Co}(\mathrm{II})$ for the synthesis of the stationary phase leads to a longer retention time when methyl gallate is eluted. Based on these results, $\mathrm{Co}$ (II) is deemed as the crucial factor in the separation process.

In addition, Feng et al. [16] reported that an increase in the imprinting factor (IF) of MIPs is a present manifestation of Co(II) ion. The synthesis of MIP PMMA-S-NAP and $\mathrm{S}$-KET resulted in IF 1.26 and 1.01. In contrast, the IF that resulted from MIP Co(II)-PMMA-S-NAP and S-KET was 2.10 and 1.90 , respectively, leading to a successful synergistic effect in printing activity. Wei et al. [17] reported that cetirizine content in ethanol was extracted with a recovery yield of $97.8 \%$. The extraction was conducted with MIP monolith where Co (II) was a chelating agent, resulting in an imprinting factor 23.5 times higher than that without Co (II). Almost all bivalent metals prefer complexes with a coordination number of 6 or an octahedral shape. The formation of octahedral complexes by bivalent metals with $3 \mathrm{~d}^{\mathrm{n}}$ configuration is high-spin (weak-field complex) or lowspin (strong-field complex) for $n=4-7$. Furthermore, transition metals with valence $>7$ coordinate to form strongfield complexes only. According to Ligand-Field Stabilization Energy (LFSE) [18], the highest stability was achieved by metal ions with configuration $\mathrm{d}^{7}$ as its $\mathrm{LFSE}=1.8 \Delta \mathrm{o}-\mathrm{P}$ $(\Delta \mathrm{o}=$ the ligand-field splitting parameter, $P=$ pairing energy). The order of octahedral complex stability is as follows: $\mathrm{Co}$ (II) $>\mathrm{Ni}$ (II) $>\mathrm{Cu}$ (II) $>\mathrm{Zn}$ (II) according to their electron configurations $\mathrm{d}^{7}, \mathrm{~d}^{8}, \mathrm{~d}^{9}$, and $\mathrm{d}^{10}$, respectively. It means that the $\mathrm{Co}$ (II) can form the most stable strong-field octahedral complex with the $\mathrm{N}$ donor atom of the 4-VP functional monomer [18], resulting in better IF for the MMIP preparation.

The use of ionic liquid (IL) as a solvent in polymer synthesis progressively grows due to several excellent chemical properties, such as high conductivity, nonflammability, thermal stability, and low vapor pressure at room temperature $[19,20]$. IL also exhibits unique solvation properties to perform discrete polar and nonpolar microenvironments. These properties solve the solubility problems when using conventional organic solvents [21]. Furthermore, IL can also accelerate the polymerization reaction [22].

DMF-DMSO-IL solvent mixture is highly recommended for the synthesis of monolith organic polymer, mostly for a polar template. In the synthesis process, DMF and DMSO dissolve the metal pivot and regulate template retention in MMIP and MIP. The use of DMSO-combined IL as a porogen will provide good solvation quality so that the detailed printing effect can be achieved [23]. The porogenic solvent also serves to strengthen complex structure monolith through polymerization [15].

In this work, MMIP was synthesized using $\mathrm{Co}$ (II) ions as the pivot of metal assembly. The solution mixture consisted of (R)-(+)-citronellal template, functional monomer (4-VP), and crosslinker (TRIM) or (EDMA) with different ratios of porogenic solvent. The porogenic solvent was prepared from a mixture of [BMIM] $\left[\mathrm{BF}_{4}\right]$ ionic liquid, DMF, and DMSO. The method used in the MMIP monolith synthesis was metalmediated molecular self-assembly (MMSA). The combination of these materials was intended to produce the polymeric stationary phase with high sensitivity and selectivity in separating enantiomeric compounds based on materials' characteristics. The MMIP monolith in this work was prepared by in situ copolymerization inside silicosteel ${ }^{\circledR}$ tubing $(100 \mathrm{~mm}$ length $\times 1.0 \mathrm{~mm}$ i.d). Then, it was applied as chiral stationary phase (CSP) in HPLC to separate and purify rac-citronellal compounds by observing several tested parameters, such as the composition and concentration of materials, column performance, separation process, flow rate, and mobile phase composition. Furthermore, the physical characteristic of the monolithic column was also considered through characterization by several instruments such as a UV-Vis and Fourier Transform Infrared (FTIR) Spectrophotometers and Scanning Electron Microscope (SEM).

Although we apply similar monomers, porogen, and metal pivot, the MMIP polymerization in this study was carried out in situ inside a $1.0 \mathrm{~mm}$ i.d. microbore silicosteel column with the template of $(\mathrm{R})-(+)$-citronellal, which is smaller than those employed by Bai et al., $4.6 \mathrm{~mm}$ i.d. with the template of mandelic acid [10], and Bodoki et al., $2.1 \mathrm{~mm}$ i.d. with the template of atenolol [12]. The different templates strongly influenced the selectivity of the columns in the MMIP. Furthermore, it was proved that a small diameter monolithic column would have various advantages over a big one, including greater homogeneity and separation efficiency, and it is environmentally friendly due to the decreased sample and reagent use. Additionally, larger diameter monolithic columns are less homogeneous, not only due to differential heating across the tube diameter but also because of the rising gravitational settling effect during the exothermic polymerization process $[1,24]$.

\section{Experimental}

2.1. Chemicals and Materials. Ethylene glycol dimethacrylate 98\% (EDMA) and trimethylolpropane trimethacrylate $90 \%$ 
(TRIM) of Tokyo Chemical Industry (TCI), Japan, were applied as crosslinking agents, while the 4-vinyl pyridine (4VP) 95\% from TCI (Japan) was used as the functional monomer. The porogenic solvent consisted of N,N-dimethylformamide $99.8 \%$ (DMF), dimethyl sulfoxide $\geq 99.9 \%$ (DMSO), and 1-butyl-3-methylimidazolium tetrafluoroborate $\geq 98 \%$ [BMIM] $\left[\mathrm{BF}_{4}\right]$ ionic liquid, 3-(trimethoxysilyl) propyl methacrylate (MAPS) 98\%, pyridine anhydrous $99.8 \%$, sodium acetate anhydrous $\geq 99 \%$, sodium hydroxide $(\mathrm{NaOH}) \quad 97 \%$, cobalt acetate tetrahydrate $\mathrm{Co}(\mathrm{Oac})_{2} \cdot 4 \mathrm{H}_{2} \mathrm{O} 99.99 \%$ for analysis, acetonitrile (ACN) for liquid chromatography, acetic acid (glacial) 100\%, $\alpha, \alpha^{\prime}$-azobisisobutyronitrile $12 \mathrm{wt} \%$ in acetone (AIBN) as the radical initiator, (R)-(+)-citronellal 90\%, and (S)-(-)-citronellal 96\% which were purchased from Sigma-Aldrich (Singapore). Methanol for GC $99.9 \%$ was purchased from J. T. BAKER (USA). Acetone $99.75 \%$ was purchased from Mallinckrodt chemical (USA). Water (Aqua Pro Injection) from Ikapharmaindo (Indonesia) and hydrochloric acid ( $\mathrm{HCl}$ ) 37\% from PT Smart Lab (Indonesia) were used for reagent preparation. Fused silica silicosteel ${ }^{\circledR}$ tubing $(100 \mathrm{~mm}$ in length, outer diameter $1 / 16$ inch, and $1.0 \mathrm{~mm}$ inner diameter) from Supelco was utilized as a column housing. All materials were high purity and used directly without further purification.

2.2. Instrumentation. The chromatographic system applied in this work was an HPLC prominence 20 from Shimadzu equipped with LabSolution software. It consisted of degasser units (DGU-20A), pumps (LC-20AD), oven (CTO-20A), UV-Vis detector (SPD-20A), a semi-micro flow cell $(2.5 \mu \mathrm{L})$, a Rheodyne 7125 injector with $2 \mu \mathrm{L}$ loop sample, and a controller (CBM-20A). FTIR-8400S of Shimadzu was used for the identification of functional groups in monoliths. Scanning Electron Microscope (SEM), Hitachi FE-SEM 1000 , was used for the morphological imaging, and UV-Vis Spectrophotometer-1601 Shimadzu was employed for the template and Co (II) removal identification.

2.3. Preparation of Fused Silica Silicosteel ${ }^{\oplus}$ Tubing as a Monolithic Column Housing. Silicosteel ${ }^{\circledR}$ tubing was pretreated through silanization prior to use $[1,25,26]$. The first step was to rinse the inside silicosteel ${ }^{\circledR}$ tubing with water three times. Afterward, the column was filled with $0.2 \mathrm{M}$ $\mathrm{NaOH}$ and left to stand for $30 \mathrm{~min}$, followed by rinsing with water, and subsequently filled with $0.2 \mathrm{M} \mathrm{HCl}$ and left to stand $30 \mathrm{~min}$. These procedures were repeated twice. After being treated with $\mathrm{NaOH}$ and $\mathrm{HCl}$, the tubing was washed with water three times, followed by acetone. All filling and washing processes were carried out with a syringe. The activated silicosteel ${ }^{\circledR}$ tubing was then filled with $30 \%$ MAPS in acetone and pyridine at a ratio of $30: 65: 5$ (MAPS: acetone: pyridine, $\mathrm{v} / \mathrm{v}$ ). Both ends of the column were closed and left at room temperature for $12 \mathrm{~h}$. This procedure was repeated twice. In the final step, the silicosteel ${ }^{\circledR}$ tubing was rinsed with acetone, cut $100 \mathrm{~mm}$ in length and $1 \mathrm{~mm}$ i.d, and ready to be filled with the monomer mixture for the monolith polymer synthesis.
2.4. Synthesis of Metal-Mediated Molecularly Imprinted Polymer (MMIP) Monolith inside Silicosteel ${ }^{\otimes}$ Tubing. The schematic representation of MMIP preparation with template and metal pivot Co (II) ion in the monolith framework can be seen in Figure 1. In this work, two kinds of MMIPs with different crosslinkers (TRIM and EDMA) were prepared, as shown in Table 1. Ionic liquid [BMIM] $\left[\mathrm{BF}_{4}\right]$ was added with porogen ratio of $[\mathrm{BMIM}]\left[\mathrm{BF}_{4}\right]: \mathrm{DMF}: \mathrm{DMSO}$ 1:1:1 and 10:1:5 (v/v) for TRIM and EDMA crosslinker, respectively. Afterward, 4-VP functional monomers, (R)(+)-citronellal template, TRIM/EDMA crosslinker monomers, cobalt acetate in DMF:DMSO $(1: 1, \mathrm{v} / \mathrm{v})$, and ionic liquid $[\mathrm{BMIM}]\left[\mathrm{BF}_{4}\right]$ were mixed in a vial. The porogen ratios of [BMIM] $\left[\mathrm{BF}_{4}\right]:$ DMF : DMSO were $1: 1: 1(\mathrm{v} / \mathrm{v})$ and 10:1:5 (v/v) for preparation of MMIPs with TRIM and EDMA as crosslinkers, respectively. The prepolymerization mixture was homogenized using the sonicator for $5 \mathrm{~min}$ and added with $1 \%$ of AIBN as the radical initiator and further homogenized for $10 \mathrm{~min}$. The homogenized mixture was then injected into the activated silicosteel ${ }^{\circledR}$ tubing (Section 2.3) using the adapter syringe. Both the column ends were closed using close-end nuts (Supelco) for in situ copolymerizations in the oven at $60{ }^{\circ} \mathrm{C}$ for $18 \mathrm{~h}$.

After the polymerization process, monolithic columns were connected with the HPLC pump and washed with methanol: acetic acid $(9: 1, \mathrm{v} / \mathrm{v})$ mixture for $4 \mathrm{~h}$ with a flow rate of $0.05 \mathrm{~mL} / \mathrm{min}$ to remove residual monomers, porogen, (R)-(+)-citronellal template, and Co (II) used in the MMIP monolith preparation. To confirm the removal of (R)(+)-citronellal template, the spectra of washing solution effluent collected every $1 \mathrm{~h}$ were recorded at the wavelength of $253 \mathrm{~nm}$. A similar procedure was also applied to estimate the amount of Co (II) removed from the MMIP column. The calibration curve of Co (II) was constructed by dissolving Co (II) acetate in the mixture of methanol: acetic acid $(9: 1, \mathrm{v} / \mathrm{v})$, which was detected at $517 \mathrm{~nm}$ by the UV-Vis spectrophotometer.

The morphological observation of the produced MMIP monolithic columns was carried out using scanning electron microscopy (SEM). Subsequently, a permeability test was performed by measuring the column's backpressure by employing the HPLC pump with the solvent of acetonitrile: water $(50: 50, \mathrm{v} / \mathrm{v})$ as the mobile phase at a constant flow rate of $0.05 \mathrm{~mL} / \mathrm{min}$. The detected pressure drop corresponding to the monolith's permeability was further calculated according to the Darcy equation [24, 27].

Metal-mediated nonimprinted polymer (MNIP), molecularly imprinted polymer (MIP), and nonimprinted polymer (NIP) were prepared with the same method. The difference was the absence of template in preparing MNIP, metal pivot in MIP, both template and metal pivot in NIP.

2.5. Separation of Rac-Citronellal Using HPLC with MMIP as the Stationary Phase. MMIP monolithic column was paired with HPLC system for the separation of rac-citronellal samples. The mixture of ACN with water was used as the mobile phase at appropriate compositions depending on the elution techniques (isocratic and gradient elutions). The 
(R)-(+)-citronellal<smiles>C=Cc1ccncc1OCC[C@@H](C)CCC=C(C)C</smiles>

Molecularly Imprinted Polymer (MIP)<smiles></smiles>

Metal-mediated Molecularly Imprinted Polymer (MMIP)
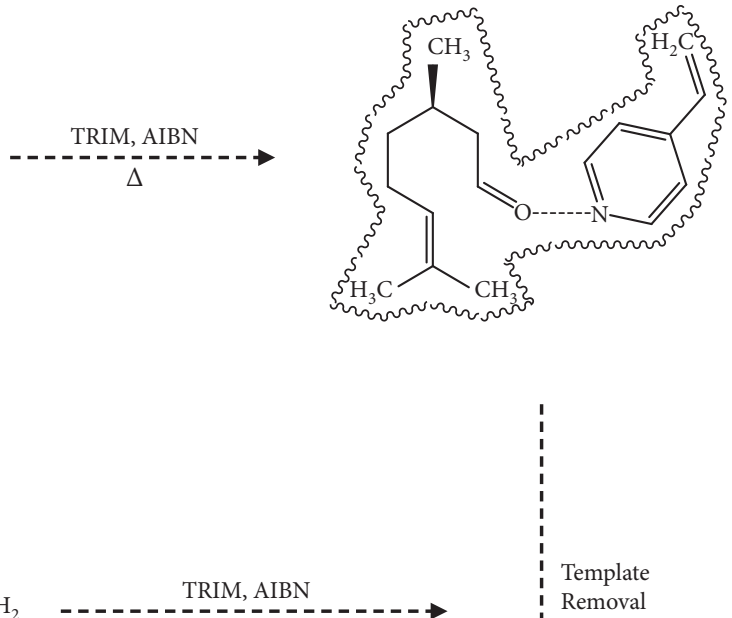
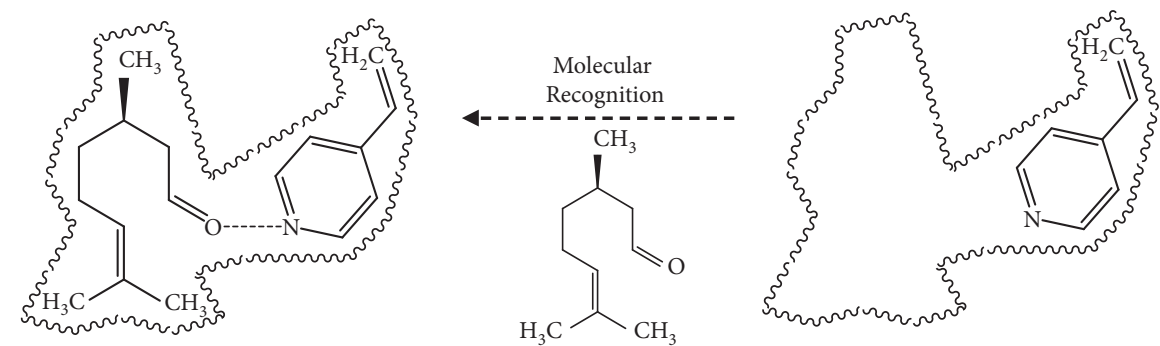

Figure 1: Schematic representation of MIP preparation and MMIP using Co(II) ion as a metal pivot for (R)-(+)-citronellal recognition.

TABle 1: Composition for the preparation of MMIP, MNIP, MIP, and NIP monolithic columns.

\begin{tabular}{|c|c|c|c|c|c|c|c|c|}
\hline Columns & $\begin{array}{c}\text { Molar ratio }(\mathrm{T}: \mathrm{M}: \mathrm{Co}: \\
\mathrm{C})\end{array}$ & $\mathrm{T}(\mathrm{mmol})$ & $\begin{array}{l}\mathrm{M} / 4-\mathrm{VP} \\
(\mathrm{mmol})\end{array}$ & $\begin{array}{c}\mathrm{Co}(\mathrm{II}) \\
(\mathrm{mmol})\end{array}$ & $\mathrm{C}(\mathrm{mmol})$ & $\begin{array}{l}{[\mathrm{BMIM}] \mathrm{BF}_{4}} \\
(\mathrm{~mL})\end{array}$ & $\begin{array}{l}\mathrm{DMF} \\
(\mathrm{mL})\end{array}$ & $\begin{array}{c}\text { DMSO } \\
(\mathrm{mL})\end{array}$ \\
\hline & & & & & TRIM & 1 & 1 & 1 \\
\hline MMIP A & $1: 5: 1: 20$ & 0.067 & 0.33 & 0.067 & 1.34 & 0.30 & 0.30 & 0.30 \\
\hline MNIP A & $-: 5: 1: 20$ & - & 0.33 & 0.067 & 1.34 & 0.30 & 0.30 & 0.30 \\
\hline MIP A & $1: 5:-: 20$ & 0.067 & 0.33 & - & 1.34 & 0.30 & 0.30 & 0.30 \\
\hline \multirow[t]{2}{*}{ NIP A } & $-: 5:-: 20$ & - & 0.33 & - & 1.34 & 0.30 & 0.30 & 0.30 \\
\hline & & & & & EDMA & 10 & 1 & 5 \\
\hline MMIP B & $1: 6: 1: 18$ & 0.10 & 0.60 & 0.10 & 1.80 & 0.82 & 0.08 & 0.40 \\
\hline MNIP B & $-: 6: 1: 18$ & - & 0.60 & 0.10 & 1.80 & 0.82 & 0.08 & 0.40 \\
\hline MIP B & $1: 6:-: 18$ & 0.10 & 0.60 & - & 1.80 & 0.82 & 0.08 & 0.40 \\
\hline NIP B & -:6:-:18 & - & 0.60 & - & 1.80 & 0.82 & 0.08 & 0.40 \\
\hline
\end{tabular}

T: template; M: functional monomer; Co: cobalt acetate; C: crosslinker. Notation of A and B in columns' name corresponds to the monoliths with crosslinker of TRIM and EDMA, respectively. The bold values showed the porogen volume ratio of [BMIM] BF4, DMF, and DMSO.

process was carried out at room temperature, at a flow rate of $0.04 \mathrm{~mL} / \mathrm{min}$, and an injection volume of $2 \mu \mathrm{L}$ and detected with the UV detector at $253 \mathrm{~nm}$. Chromatogram profiles for each sample were then observed and calculated for the resolution of each peak. The same procedure was carried out for MNIP, MIP, and NIP as the stationary phase.

\section{Results and Discussion}

3.1. Synthesis and Characterization of Metal-Mediated Molecularly Imprinted Polymer (MMIP) Monolith. Silicosteel column was pretreated in advance through silanization before it was used as the column housing for MMIP, MNIP, 
MIP, and NIP monoliths. The silanization process was carried out by hydrolyzing the column with acid and base solutions $(\mathrm{NaOH}$ and $\mathrm{HCl})$. MAPS was added to the column to facilitate covalent bonds forming between the inner wall surfaces of the silicosteel column and polymer. Silanization reaction on the inner wall surface of the silicosteel column occurred between the silanol group and the methoxy group of MAPS.

From the synthesis, two kinds of monoliths with the crosslinkers of TRIM and EDMA were obtained. The polymerization of MMIP, MNIP, MIP, and NIP monoliths was conducted in situ or using the one-pot method inside microbore columns made of the silicosteel with an inner diameter of $1 \mathrm{~mm}$. The method was preferred due to the following advantages: it showed a higher enantiomer resolution to separate chiral compounds, faster synthesis than other polymerization methods, provided reasonable control to achieve desired characteristics of the monolith through optimization of chemical and physical parameters, and was easy to perform [28]. A microbore monolith column $(1 \mathrm{~mm}$ i.d) was used for its easiness to be paired with the HPLC system without modification as compared to the capillary column, and small quantities of enantiomer samples were also another advantage. Additionally, the use of fewer solvents made it more economical and environmentally friendly. The synthesis of monolith inside large-diameter columns is still challenging due to the unequal heating along the column and gravitational settling effects [29].

The template of (R)-(+)-citronellal and $\mathrm{Co}(\mathrm{II})$ used during the MMIP A monolith synthesis had been removed prior to its application as a chiral stationary phase (CSP) in HPLC by eluting/washing the MMIP monolithic column with a mixture of methanol and acetic acid $(9: 1, \mathrm{v} / \mathrm{v})$. As shown in Figure 2, the template of $(\mathrm{R})-(+)$-citronellal was entirely removed from the MMIP A column after the $4^{\text {th }}$ washing as indicated by zero absorbance in the spectra.

Several studies have reported that the metal pivot is simultaneously released with the template $[12,30,31]$. According to Table 1, the Co(II) ion amount in the MMIP A monolith preparation was $8560 \mathrm{ppm}$, and the total Co (II) removed from the polymer was about $94.2 \%$ (Table 2) after washing the column with the mixture of methanol and acetic acid $(9: 1)$ for $4 \mathrm{~h}$. The remaining $5.8 \%$ of cobalt is perhaps still present in the MMIP A monolith, and some may be lost because it is not bound to the monolith. The quantification of (R)-(+)-citronellal template and Co (II) on the MMIP B column was conducted in a similar way as in the MMIP A. It was found that a longer washing time of $8 \mathrm{~h}$ was required for the complete removal of the template and the metal pivot. This difference may be due to the higher amount of both components during the preparation of the MMIP B monolith, as shown in Table 1. As shown in Figure 1, after template removal, the imprint of the template remained in the polymer matrix. According to the imprinted matrix template, a pair of enantiomers passing through the polymer monolith would show the elution sequence. The enantiomer used as the template would be retained longer in the monolith column $[32,33]$.

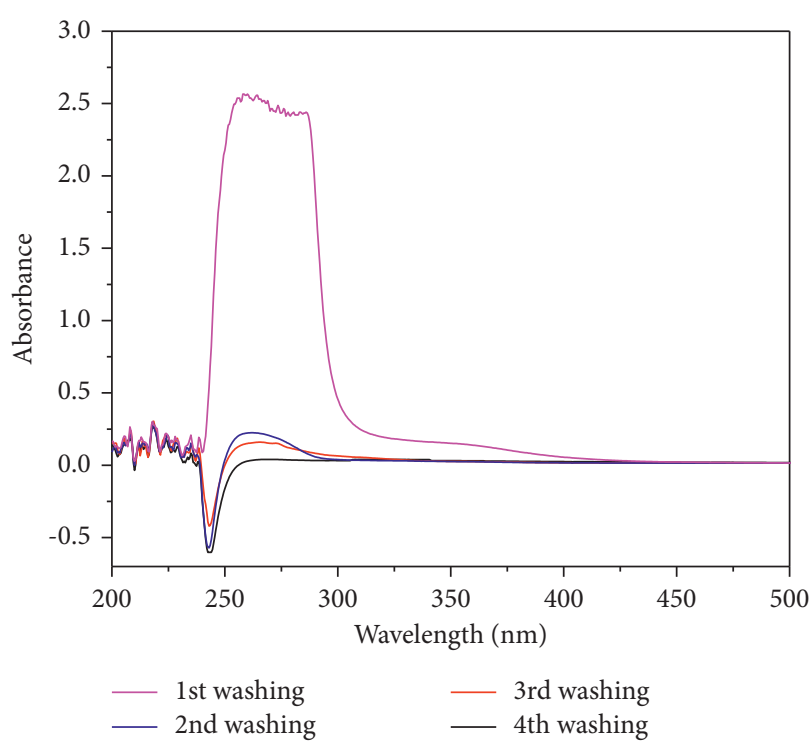

FIGURE 2: UV spectra of (R)-(+)-citronellal after removed from the MMIP A column using the HPLC pump with the eluent mixture of methanol and acetic acid $(9: 1, \mathrm{v} / \mathrm{v})$ at a flow rate of $0.05 \mathrm{~mL} \mathrm{~min}^{-1}$. The measurement wavelength was $253 \mathrm{~nm}$, and every step of washing was $1 \mathrm{~h}$.

TABLe 2: Analysis of the cobalt acetate content after washing sequence from the MMIP A column.

\begin{tabular}{|c|c|c|}
\hline Sample & Co (II) absorbance & Concentration (ppm) \\
\hline $1^{\text {st }}$ washing solution & 0.086 & 1770 \\
\hline $2^{\text {nd }}$ washing solution & 0.105 & 2086.67 \\
\hline $3^{\text {rd }}$ washing solution & 0.106 & 2103.33 \\
\hline $4^{\text {th }}$ washing solution & 0.106 & 2103.33 \\
\hline Tota & & 8063.33 \\
\hline
\end{tabular}

The initial amount of Co (II) used for the MMIP monolith A synthesis was $8560 \mathrm{ppm}$, every step washing was $1 \mathrm{~h}$, detection wavelength was $517 \mathrm{~nm}$, and the washing solution was a mixture of methanol and acetic acid $(9: 1, \mathrm{v} /$ v).

The synthesized monoliths were subsequently characterized by FTIR. It was found that the IR spectra (Figure 3) of the monoliths prepared using TRIM and EDMA crosslinkers did not show different characteristics. However, there was a difference in the absorption sharpness at $1729 \mathrm{~cm}^{-1}$. MMIP A monolith had a sharper absorption with a higher \% transmittance than MMIP B monolith absorption. This was because TRIM with 3 methacrylate groups had 3 carbonyl groups, while EDMA with 2 methacrylate groups had 2 carbonyl groups vibrating in that area. The more carbonyl groups in the monolith, the stronger the absorption shown by the FTIR spectra. All monoliths exhibited identical characteristic absorption at $3407-3445 \mathrm{~cm}^{-1}$ (OH group), except for MNIP B and MIP B, which showed weak absorption intensities. Other characteristic adsorptions appeared at $1725-1731 \mathrm{~cm}^{-1}(\mathrm{C}=\mathrm{O}$ group), $1642-1663 \mathrm{~cm}^{-1}$ ( $\mathrm{C}=\mathrm{C}$ group), and $1109-1159 \mathrm{~cm}^{-1}$ (C-O group). The result also showed absorptions around $527 \mathrm{~cm}^{-1}$ and $756 \mathrm{~cm}^{-1}$ associated with the deformation of the C-N-C 

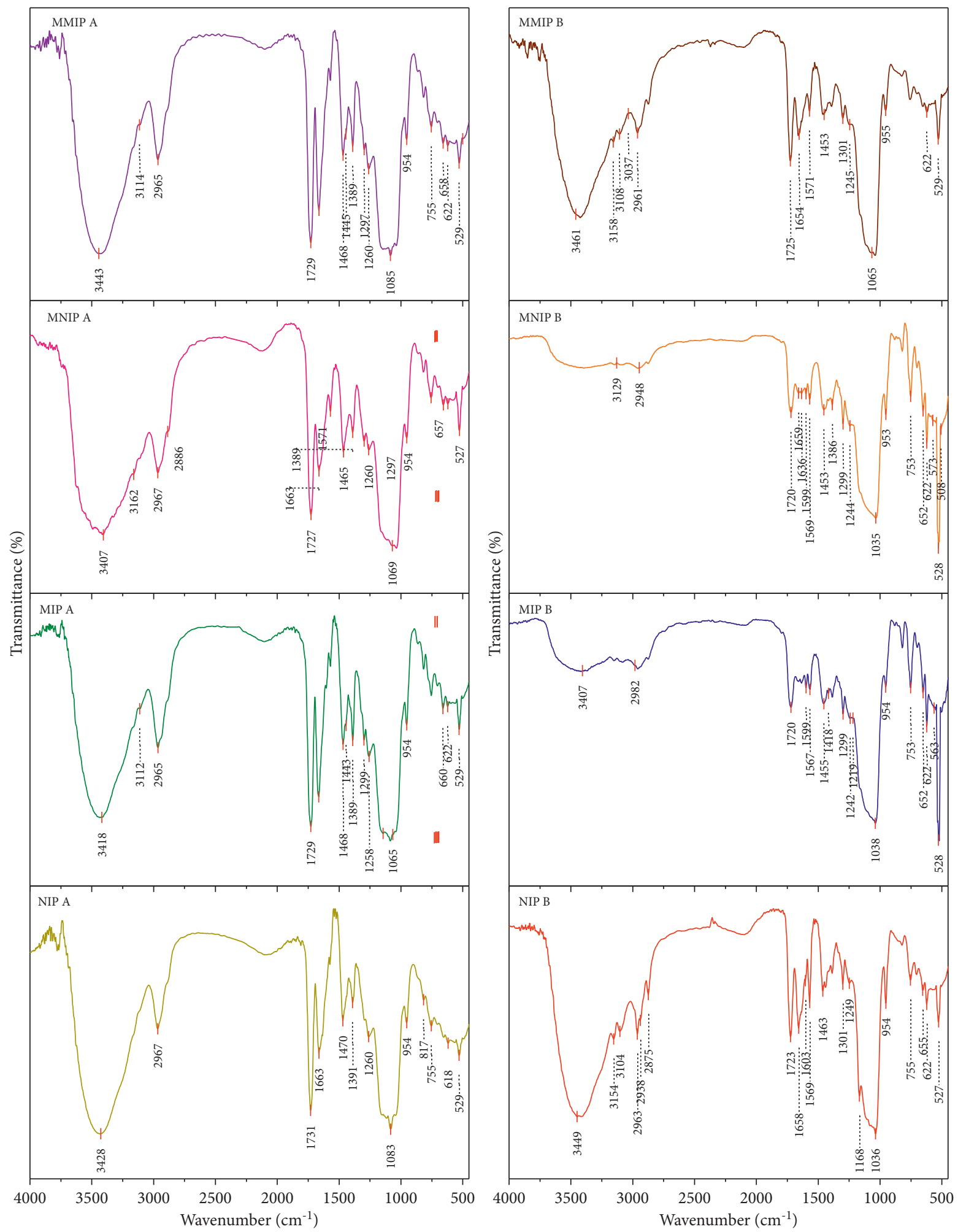

FIgURE 3: FTIR spectra of MMIP, MNIP, MIP, and NIP monoliths. The A and B notations correspond to the monoliths with the crosslinker of TRIM and EDMA, respectively (see Table 1).

group and $\mathrm{C}-\mathrm{H}$ aromatic substitution from the 4-VP functional monomer. The metal presence in the monolith could be observed around the $2050-1755 \mathrm{~cm}^{-1}$ (Co-H adsorption), $610 \mathrm{~cm}^{-1}$ (linear $\mathrm{Co}-\mathrm{N}$ ), and $565 \mathrm{~cm}^{-1}$ (Co-O bending) regions and associated with the coordination of Co (II) with the atomic donor of the ligand [34, 35].

The surface morphology of the monolith polymer was observed using SEM (Figures 4 and 5). The monolith 

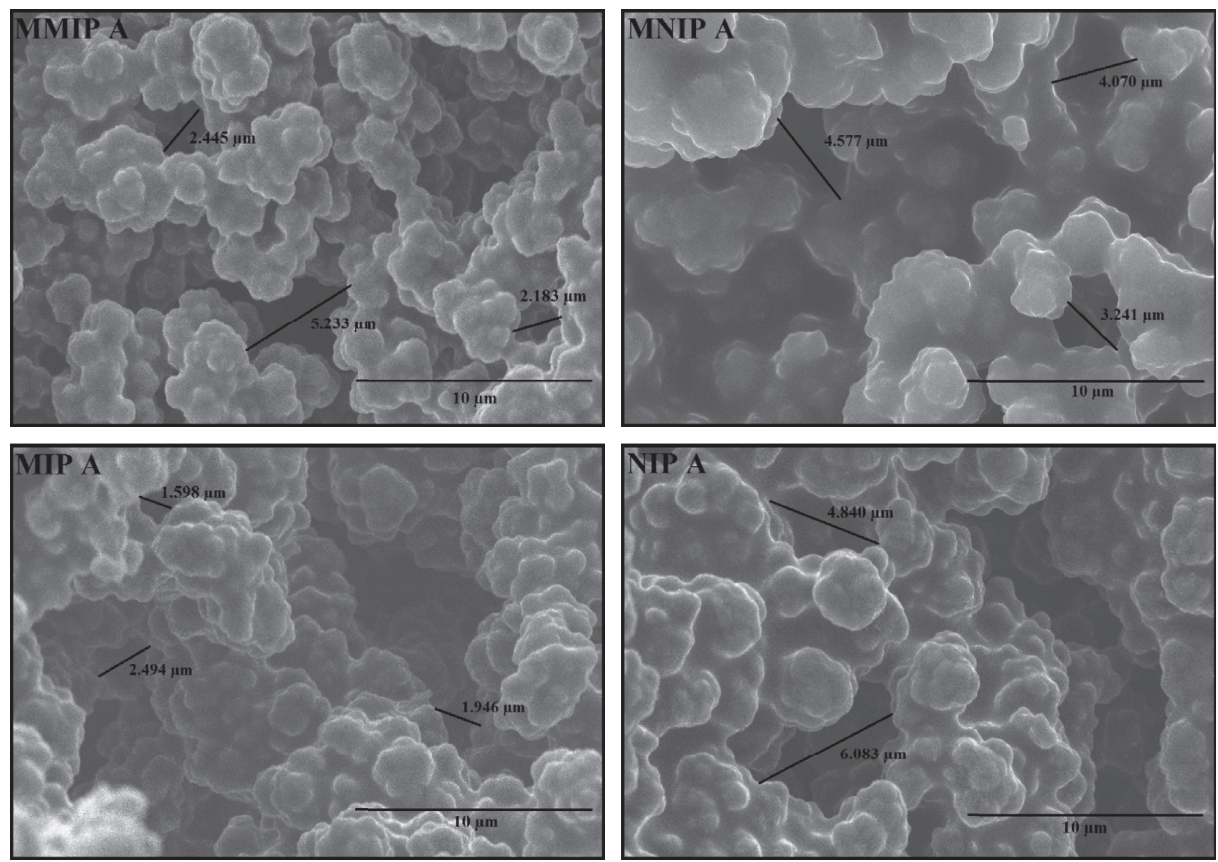

FIGURE 4: SEM images of monolith prepared with TRIM as the crosslinker at 5000x magnification. The monolith composition can be seen in Table 1.
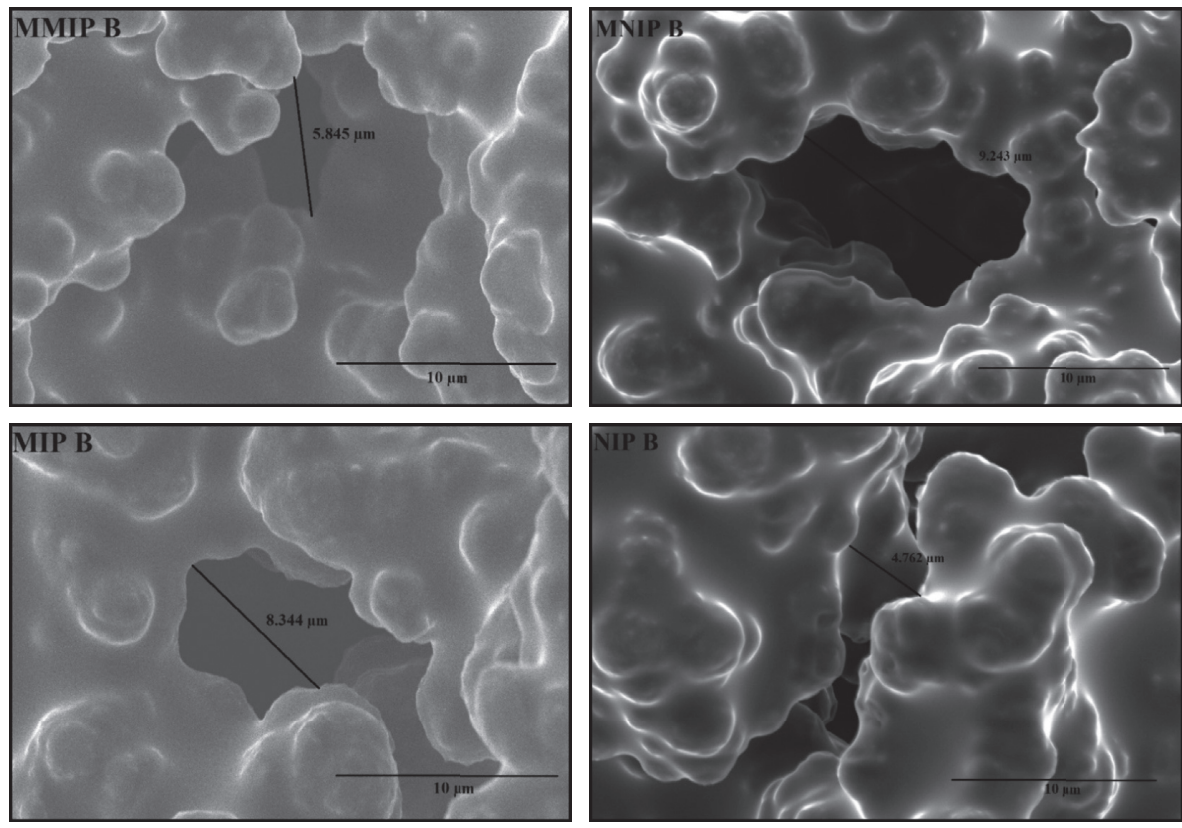

FIGURE 5: SEM images of monolith prepared with EDMA as the crosslinker at 5000x magnification. The monolith composition can be seen in Table 1.

morphological structures of MMIP, MNIP, MIP, and NIP showed dense globules formation with interconnected pores forming a continuous porous material. The spaces between globules allowed a flow to pass the through-pore, which could cause the convective flow of the mobile phase. The SEM images indicated no significant difference between MMIP or MNIP monolith contained Co(II) as the metal pivot compared to the NIP and MIP monolith without the metal pivot. However, the comparison on the surface morphology of monoliths prepared with different crosslinkers, TRIM (Figure 4) and EDMA (Figure 5), showed significant morphological differences. The use of EDMA resulted in a monolith with larger globules and through-pore sizes than that of TRIM. The result indicated that the composition of functional and crosslinking monomer, porogen, and metal as pivot significantly 
TABLE 3: Column permeability of MMIP, MNIP, MIP, and NIP monoliths.

\begin{tabular}{lr}
\hline Monolithic column & Permeability $\left(\mathrm{m}^{2}\right)$ \\
\hline MMIP A & $1.74 \times 10^{-13}$ \\
MNIP A & $2.90 \times 10^{-13}$ \\
MIP A & $4.35 \times 10^{-13}$ \\
NIP A & $2.18 \times 10^{-13}$ \\
MMIP B & $2.49 \times 10^{-13}$ \\
MNIP B & $1.45 \times 10^{-13}$ \\
MIP B & $2.90 \times 10^{-13}$ \\
NIP B & $2.18 \times 10^{-13}$ \\
\hline
\end{tabular}

TABLE 4: The isocratic elution of (R)-(+)-citronellal and (S)-(-)-citronellal using 10\% ACN (in water) using MMIP, MNIP, MIP, and NIP monoliths with TRIM as a crosslinker.

\begin{tabular}{|c|c|c|c|c|}
\hline Monolithic column & Sample & $t_{0}(\min )$ & $t_{\mathrm{r}}(\min )$ & $k^{\prime}$ \\
\hline \multirow{2}{*}{ MMIP A } & (R)-(+)-citronellal & 1.72 & 3.64 & 1.12 \\
\hline & (S)-(-)-citronellal & 1.72 & 3.35 & 0.95 \\
\hline \multirow{2}{*}{ MNIP A } & (R)-(+)-citronellal & 1.72 & 3.25 & 0.89 \\
\hline & (S)-(-)-citronellal & 1.72 & 3.65 & 1.12 \\
\hline \multirow{2}{*}{ MIP A } & (R)-(+)-citronellal & 1.72 & 3.89 & 1.26 \\
\hline & (S)-(-)-citronellal & 1.72 & 3.89 & 1.26 \\
\hline \multirow{2}{*}{ NIP A } & (R)-(+)-citronellal & 1.72 & 3.56 & 1.07 \\
\hline & (S)-(-)-citronellal & 1.72 & 3.62 & 1.10 \\
\hline
\end{tabular}
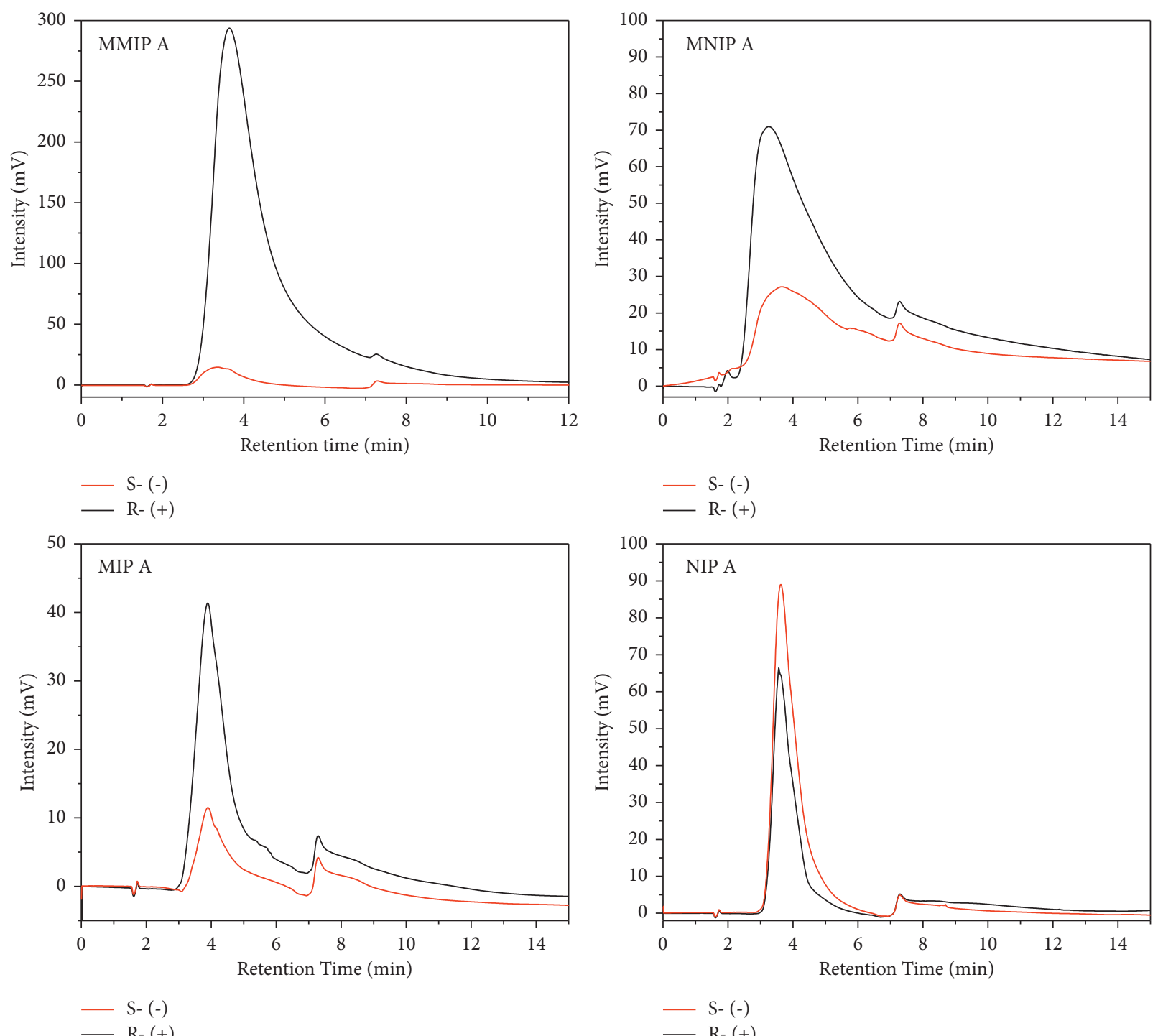

FIgURE 6: Comparison of MMIP, MNIP, MIP, and NIP monoliths with TRIM as a crosslinker for the elution of (R)-(+)-citronellal and (S)$(-)$-citronellal. The flow rate of $0.04 \mathrm{~mL} / \mathrm{min}$ and the mobile phase of $10 \%$ acetonitrile in water under the isocratic method were applied. 
TABLE 5: Enantiomer separation with a variation in mobile phase composition on monolithic columns prepared with a different crosslinker.

\begin{tabular}{ccccccccc}
\hline Column & $\mathrm{ACN}(\%, \mathrm{v} / \mathrm{v})$ & $t_{r}^{1}(\mathrm{~min})$ & $t_{r}^{2}(\min )$ & $t_{0}(\min )$ & $\mathbf{k}_{t_{R} 1}^{\prime}$ & $\mathbf{k}_{t_{R} 2}^{\prime}$ & $\alpha$ & - \\
\hline \multirow{2}{*}{ MMIP A } & 10 & 4.03 & - & 1.72 & 1.34 & - & $R_{s}$ \\
\multirow{2}{*}{ MMIP B } & 10 & 4.81 & 5.63 & 1.72 & 1.80 & 2.27 & 1.26 & 0.50 \\
& 40 & 8.67 & 9.51 & 1.72 & 4.04 & 4.53 & 1.12 & 0.32 \\
\hline
\end{tabular}

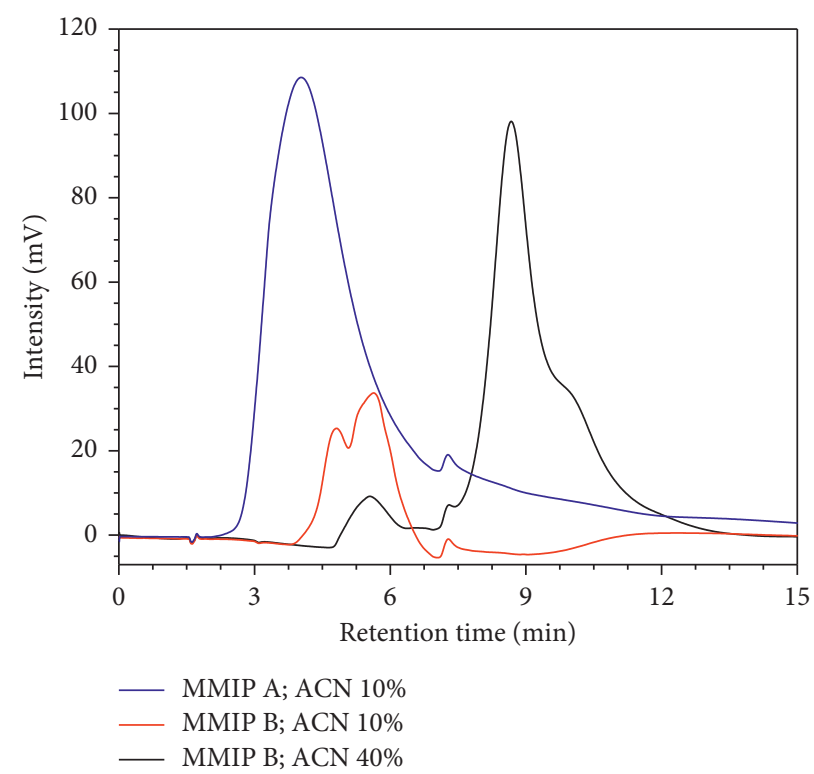

Figure 7: The effect of different crosslinkers employed in the separation of rac-citronellal. The isocratic elution using ACN/water as the mobile phase with a flow rate of $0.04 \mathrm{~mL} / \mathrm{min}$ was used.

affected the morphology of the synthesized monoliths $[15,36]$.

Permeability measurement was carried out to confirm the mobile phase flow passes through the monolith's pores channel. As shown in Table 3, monoliths imprinted without Co (II) ions (MIP A and MIP B monoliths) showed a high permeability, with the MIP A monolithic column exhibiting the highest permeability value compared to the other synthesized monoliths. The increase in the permeability of the monolithic column was proportional to the larger through-pore size. In other words, the use of metal ions as a pivot in the prepolymerization mixture generated smaller through-pore sizes of the resulting monoliths.

Based on the SEM and permeability analysis, the MMIP B monolithic column demonstrated better quality than MMIP A. The globule and the flow-through pore size of MMIP B were larger than those of MMIP A, following the result of permeability analysis. The difference in the composition of template, AIBN, and metal affected the resulting monolith characteristics. The exact amount of added AIBN initiator in the synthesis of MMIP A was higher than that in MMIP B, although it was proportional to the total amount of monomer and the template (equal to $1 \% \mathrm{w} / \mathrm{v})$. It indicated that the more monomers for synthesis were, the more AIBN for the monomer solution mixture would be. The use of excessive initiators led to more polymer nuclei formed at the start of the polymerization process, each of which got bigger and was interconnected to form a network. As a result, the monolith was too dense and less elastic, causing MMIP A to have a smaller throughpore size than MMIP B.

Generally, the quantification of monoliths' pores size for HPLC application was performed by the inverse size exclusion chromatography (ISEC) as shown in our previous work [1, 24, 27, 29, 37]. Although this method is ideal for "wet" chromatography, column destruction cannot be avoided. Therefore, we did not apply this method in the present work. To estimate the pore size of the monolith (although it is not quantitative), we use SEM morphology and permeability only. If the column permeability is high, it means that the pore formation of the monolith is good because the solvent can pass the column faster via the flowthrough pore of the synthesized monolith. The results of the permeability analysis given in Table 3 confirmed that MMIP column A has lower permeability than MMIP column B. It means that the ability of MMIP column A to pass solvents is lower than that of MMIP column B. The MMIP A column produces a back pressure of $0.5 \mathrm{MPa}$, while the MMIP B column has a lower back pressure of $0.2 \mathrm{MPa}$. From the surface morphology analysis using the SEM data (Figures 4 and 5), the MMIP A column has a flow-through pore in the range of $2.18-5.24 \mu \mathrm{m}$, while the MMIP B column is in the range of $5.85-9.24 \mu \mathrm{m}$. 

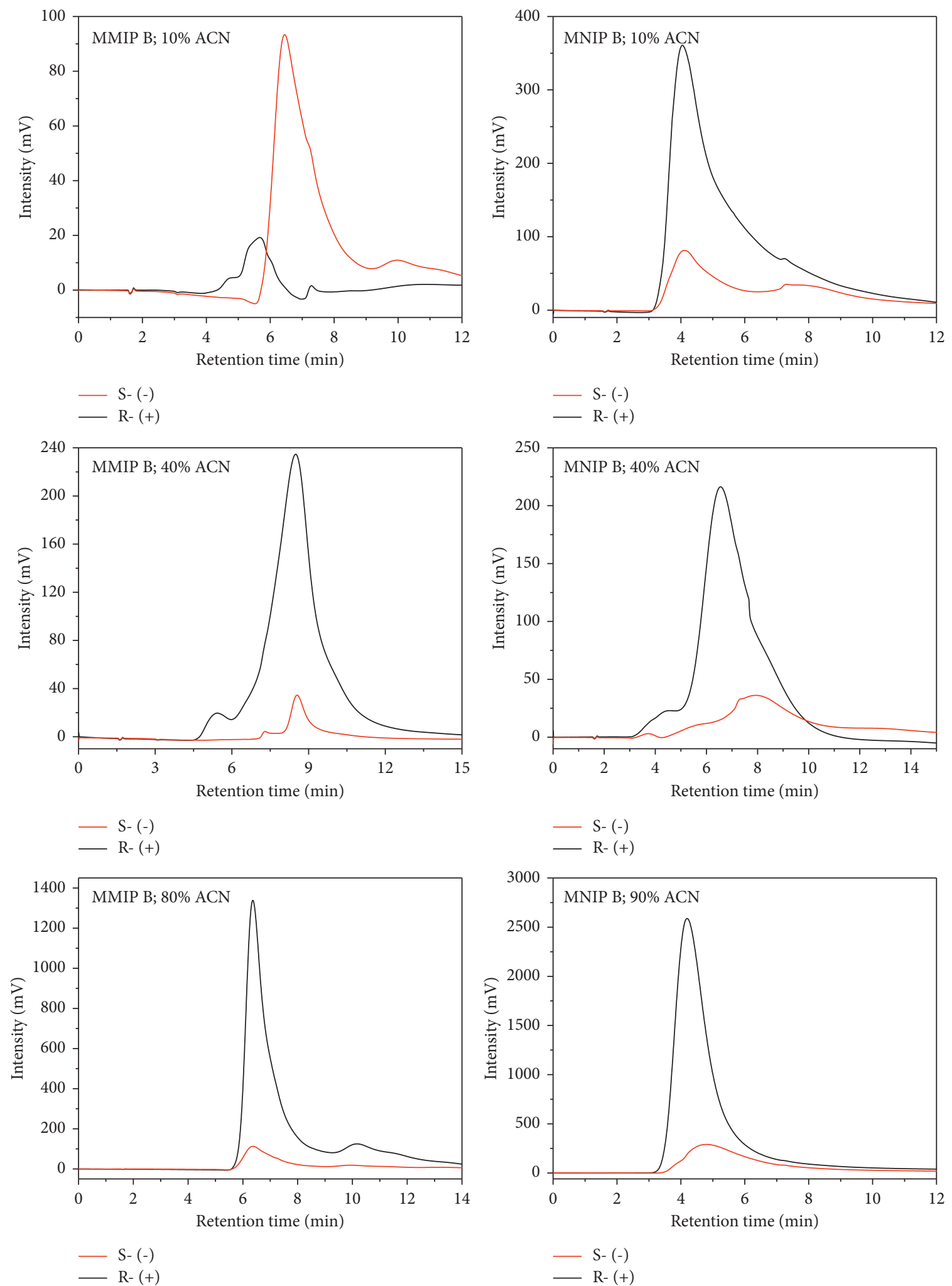

FIGURE 8: The effect of ACN concentration in water as the mobile phase to the retention time of (R)-(+)-citronellal and (S)-(-)-citronellal with MMIP B and MNIP B columns with the flow rate of $0.04 \mathrm{~mL} / \mathrm{min}$.

3.2. Application of MMIP Monolith as the Chiral Stationary Phase. The monolithic columns have a more dominant mesoporous size than micropores or macropores $[1,24]$. If the macropores are too prevalent, the sample and mobile phase will come out from the column faster; thus, the separation is usually less optimal or causes unsatisfactory 
TABLE 6: Capacity factor ( $\mathrm{k}^{\prime}$ ) on the MNIP B column using a mobile phase with different ACN compositions using the isocratic elution method.

\begin{tabular}{|c|c|c|c|c|c|}
\hline Column & $\mathrm{ACN}$ in water $(\%, \mathrm{v} / \mathrm{v})$ & Sample & $t_{0}(\min )$ & $t_{\mathrm{r}}(\min )$ & $k^{\prime}$ \\
\hline \multirow{6}{*}{ MMIP B } & \multirow{2}{*}{10} & (R)-(+)-citronellal & 1.72 & 5.67 & 2.30 \\
\hline & & (S)-(-)-citronellal & 1.72 & 6.45 & 2.75 \\
\hline & \multirow{2}{*}{40} & (R)-(+)-citronellal & 1.72 & 8.49 & 3.94 \\
\hline & & (S)-(-)-citronellal & 1.72 & 8.55 & 3.97 \\
\hline & \multirow{2}{*}{80} & (R)-(+)-citronellal & 1.72 & 6.42 & 2.74 \\
\hline & & (S)-(-)-citronellal & 1.72 & 6.37 & 2.70 \\
\hline \multirow{6}{*}{ MNIP B } & \multirow{2}{*}{10} & (R)-(+)-citronellal & 1.72 & 4.04 & 1.35 \\
\hline & & (S)-(-)-citronellal & 1.72 & 4.11 & 1.39 \\
\hline & \multirow{2}{*}{40} & (R)-(+)-citronellal & 1.72 & 8.55 & 3.97 \\
\hline & & (S)-(-)-citronellal & 1.72 & 7.95 & 3.63 \\
\hline & \multirow{2}{*}{90} & (R)-(+)-citronellal & 1.72 & 4.19 & 1.44 \\
\hline & & (S)-(-)-citronellal & 1.72 & 4.80 & 1.79 \\
\hline
\end{tabular}

completion of sample separation. Such monoliths are less favorable for the enantio-separation of small molecules such as rac-citronellal essential oil. Mesopores provided sufficient space for interaction and adequate binding capacity between samples with the stationary phase [27], which was beneficial for separation research in biochemistry, environmental sciences, and pharmacy [37]. TRIM and EDMA have been widely used as a crosslinker monomer in the manufacture of imprinted monoliths $[10,38]$. Interaction of template with functional monomer is considerably more prevalent in TRIM than in EDMA as a crosslinker. In other words, the interaction of the EDMA-template is more dominant than the TRIM template. This condition would affect the selectivity of imprinted monoliths [39].

According to data described in Table 4 and Figure 6, monoliths prepared with templates and metal pivot (MMIP A, TRIM as a crosslinker) showed that (R)-(+)-citronellal was retained in the stationary phase longer than (S)$(-)$-citronellal. On the other hand, (S)-(-)-citronellal was retained longer in MNIP A and NIP A column (monoliths without templates), while MIP eluted (R)-(+)-citronellal and (S)-(-)-citronellal with no significant difference in retention time. Therefore, it can be concluded that adding metal and template in the monolith is crucial and influential to separate enantiomer compounds.

Table 5 and Figure 7 show that the MMIP B column prepared with EDMA crosslinker displayed the ability to separate rac-citronellal compounds with a selectivity of 1.26 and a resolution of $0.50 \mathrm{in} \mathrm{ACN/water}(10 / 90, \mathrm{v} / \mathrm{v})$ and 1.12 and 0.32 in $\mathrm{ACN} /$ water $(40 / 60, \mathrm{v} / \mathrm{v})$. On the contrary, the separation of rac-citronellal compounds with the MMIP A column was considered ineffective. Accordingly, we examined the imprinted monoliths with EDMA crosslinker for further experiments.

The variation in acetonitrile composition as the mobile phase was also investigated by MMIP B and MNIP B column, affecting the production capacity factor ( $\left.\mathbf{k}^{\prime}\right)$. Figure 8 shows the CSP monolith column with various acetonitrile compositions indicating a good separation. Some (S)-(-)-citronellals retained longer than (R)$(+)$-citronellal in the column as the compound was more distributed to the stationary phase than to the mobile

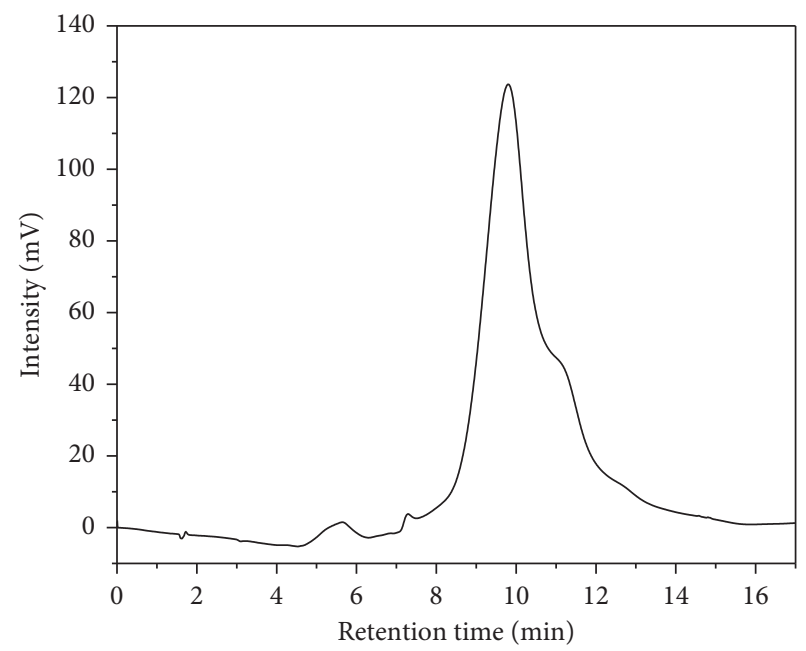

FIgURE 9: Chromatogram of rac-citronellal separation using MMIP B column. Mobile phase (A) $\mathrm{H}_{2} \mathrm{O}$ and mobile phase (B) acetonitrile $90 \%$ in (A), gradient elution: $70 \%-75 \%$ B for 8 mins, $75 \%-85 \%$ for 9 mins; detection wavelength at $253 \mathrm{~nm}$; flow rate $0.04 \mathrm{~mL} / \mathrm{min}$.

phase. MNIP B column did not use templates during the synthesis process; thus, the enantiomeric pairs (R)(+)-citronellal and (S)-(-)-citronellal exhibited the same ability to interact with polymer matrix when they were eluted through the column. This finding revealed that the use of acetonitrile at a lower ratio than water in the mixture of mobile phase caused the citronellal enantiomers to have a significant difference in residence time. The supporting data in Table 6 confirmed this finding. The use of the MMIP $\mathrm{B}$ column in different concentrations of $\mathrm{ACN}$ of $10 \%$ and $40 \%$ resulted in different retention times at 0.78 and 0.60 minutes, respectively.

Monolith columns imprinted by templates provide a more substantial recognition site as the stationary phase than those without templates, leading to better selectivity [10]. Thus, the rac-citronellal separation was optimized with the elution gradient method on MMIP B which was considered as the best column than the other 7 monolithic columns. CSP column had a $1: 1$ template to Co (II) ion ratio and a 1:6 template to functional monomer ratio. 
TABLE 7: Enantiomer separation of rac-citronellal on the MMIP B column using the gradient elution method.

\begin{tabular}{lccccccc}
\hline Gradient program & $t_{r}^{1}(\min )$ & $t_{r}^{2}(\min )$ & $t_{0}(\min )$ & $\mathbf{k}_{\mathbf{t}_{\mathrm{R}} 1}{ }^{\prime}$ & $\mathbf{k}_{\mathbf{t}_{\mathrm{R}}{ }^{\prime}}$ & $\alpha$ & $R_{s}$ \\
\hline $\mathrm{X}$ & 9.80 & 10.79 & 1.72 & 4.70 & 5.28 & 1.12 \\
$\mathrm{Y}$ & 39.26 & 41.83 & 1.72 & 21.84 & 23.33 & 1.07 & 1.71 \\
\hline
\end{tabular}

$t_{r}^{1}$ and $t_{r}^{2}$ correspond to the retention time of (S)-(-)-citronellal and (R)-(+)-citronellal, respectively; X: mobile phase and gradient program are the same as in Figure 9; Y: mobile phase and gradient program are the same as in Figure 10.

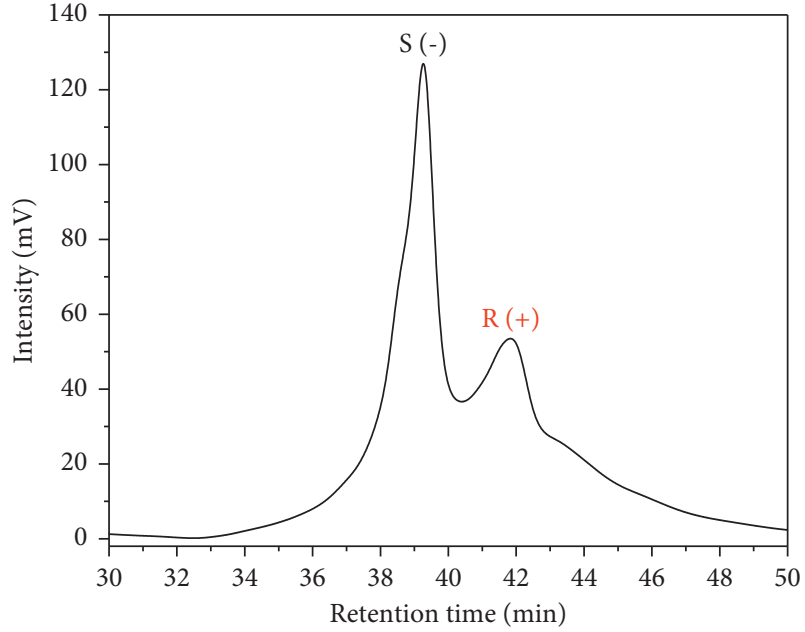

FIGURE 10: Chromatogram of rac-citronellal separation using MMIP B column. Mobile phase (A) $\mathrm{H}_{2} \mathrm{O}$ and mobile phase (B) acetonitrile $90 \%$ in (A), gradient elution: $30-60 \%$ B for 12 mins, $60-70 \%$ B for 18 mins, $70-20 \%$ for 30 mins, detection wavelength at $253 \mathrm{~nm}$; flow rate $0.04 \mathrm{~mL} / \mathrm{min}$.

The isocratic method was not efficient in separating the enantiomeric rac-citronellal compounds; therefore, the elution gradient method was performed at the same flow rate $(0.04 \mathrm{~mL} / \mathrm{min})$. A lower concentration of acetonitrile used as the mobile phase made the separation more effective. Consequently, the elution gradient method required water as the dominant mobile phase. The first peak started to appear at 6 minutes and the second at 10 minutes. However, the resolution $(R s)$ was not good as indicated; only a small split peak appeared (Figure 9 and Table 7). Based on the obtained chromatogram in Figure 9, the elution gradient method had to be modified to produce better resolution (Rs) of raccitronellal, as shown in Figure 10 and Table 7.

The MMIP B as CSP column (Figure 10) exhibited a different performance in the rac-citronellal separation under the gradient elution method. The compound was eluted longer in the column and came out at a retention time of 38 mins, confirming that the synthesized monolith column interacted strongly with water as the solvent. A dominant water solvent used as HPLC mobile phase led to longer elution of rac-citronellal in the column. The monolith column contained several $\mathrm{O}$ donor atoms from a TRIM/ EDMA crosslinker monomer and $\mathrm{N}$ donor atoms from the 4-VP functional monomer. As a result, protic solvents such as water enabled interaction forces among the hydrogen bonding molecules on the column and the water solvent. This finding is in accordance with Bodoki et al. [12], explaining the selection of functional monomer, crosslinker monomer, and porogen type in the monolith preparation. The consistency of rac-citronellal separation using monolith columns as chiral stationary phases (CSPs) in high-performance liquid chromatography (HPLC) is challenging to maintain. Therefore, it was complicated to obtain separation with an excellent resolution of rac-citronellal samples. The challenge of using MMIPs as CSPs in HPLC was a low separation efficiency due to slow interaction kinetics and heavy peak broadening [40].

\section{Conclusions}

Chiral stationary phase column of poly-MMIP-(4VPEDMA-IL) monolith is more effective than poly-MMIP(4VP-TRIM-IL) monolith for separating enantiomeric compounds of the rac-citronellal essential oil. The use of $\mathrm{Co}$ (II) as the metal pivot in the monolith column produces a denser material structure, larger and stiffer globules, and larger size of flow-through pore than that without $\mathrm{Co}$ (II) metal mediation.

\section{Data Availability}

The data used to support the findings of this study are available from the corresponding author upon request.

\section{Conflicts of Interest}

The authors declare that they have no conflicts of interest.

\section{Acknowledgments}

The author (AS) would like to thank the Directorate of Research and Community Service (DRPM), Directorate General of Research Empowerment and Development, Ministry of Research and Technology, for the research funding through WCR Scheme 2021.

\section{References}

[1] A. Sabarudin, J. Huang, S. Shu, S. Sakagawa, and T. Umemura, "Preparation of methacrylate-based anion-exchange monolithic microbore column for chromatographic separation of DNA Fragments and Oligonucleotides," Analytica Chimica Acta, vol. 736, pp. 108-114, 2012.

[2] C. Acquah, C. K. S. Moy, M. K. Danquah, and C. M. Ongkudon, "Development and characteristics of polymer monoliths for advanced LC Bioscreening applications: a Review," Journal of Chromatography B, vol. 1015-1016, pp. 121-134, 2016.

[3] N. Wang, S. He, and Y. Zhu, "Low-level Bromate analysis by ion chromatography on a polymethacrylate-based monolithic 
column followed by a Post-column reaction," European Food Research and Technology, vol. 235, no. 4, pp. 685-692, 2012.

[4] K. Meller, M. Szumski, and B. Buszewski, "Microfluidic reactors with immobilized enzymes-Characterization, dividing, perspectives," Sensors and Actuators B: Chemical, vol. 244, pp. 84-106, 2017.

[5] G. Wulff, "Molecular imprinting in Cross-Linked materials with the Aid of molecular templates- A way towards Artificial Antibodies," Angewandte Chemie International Edition in English, vol. 34, no. 17, pp. 1812-1832, 1995.

[6] J. Kupai, E. Rojik, P. Huszthy, and G. Szekely, "Role of Chirality and Macroring in imprinted polymers with Enantiodiscriminative Power," ACS Applied Materials \& Interfaces, vol. 7, no. 18, pp. 9516-9525, 2015.

[7] N. Lavignac, K. R. Brain, and C. J. Allender, "Concentration dependent Atrazine-Atrazine complex formation Promotes selectivity in Atrazine imprinted polymers," Biosensors and Bioelectronics, vol. 22, no. 1, pp. 138-144, 2006.

[8] G. Vasapollo, R. D. Sole, L. Mergola et al., "Molecularly imprinted polymers: present and Future Prospective," International Journal of Molecular Sciences, vol. 12, no. 9, pp. 5908-5945, 2011.

[9] S. Harrisson, S. R. Mackenzie, and D. M. Haddleton, "Unprecedented solvent-induced acceleration of free-radical propagation of methyl methacrylate in ionic liquids," Chemical Communications, vol. 2, no. 23, pp. 2850-2851, 2002, Electronic supplementary information (ESI) available: sample PLP-GPC traces and full experimental data See http://www.rsc.org/suppdata/cc/b2/b209479g/.

[10] L.-H. Bai, X.-X. Chen, Y.-P. Huang, Q.-W. Zhang, and Z.-S. Liu, "Chiral separation of racemic mandelic acids by Use of an ionic liquid-mediated imprinted monolith with a metal ion as self-assembly pivot," Analytical and Bioanalytical Chemistry, vol. 405, no. 27, pp. 8935-8943, 2013.

[11] J. E. Lofgreen and G. A. Ozin, "Controlling morphology and Porosity to Improve performance of molecularly imprinted Sol-Gel silica," Chemical Society Reviews, vol. 43, no. 3, pp. 911-933, 2014.

[12] A. E. Bodoki, B. C. Iacob, L. E. Gliga et al., "Improved Enantioselectivity for atenolol employing pivot based molecular imprinting," Molecules, vol. 23, pp. 1-20, 2018.

[13] B.-C. Iacob, A. E. Bodoki, and L. O. E. Bodoki, Metal-Ligand Interactions in Molecular ImprintingIntech Open, Croatia, 2018.

[14] Y. K. Sun, M. Jia, J. Yang, Y.-P. Huang, Z.-S. Liu, and H. A. Aisa, "A strategy of utilizing $\mathrm{Zn}(\mathrm{II})$ as Metallic pivot in room temperature ionic liquid to Prepare molecularly imprinted polymers for compound with Intramolecular hydrogen bonds," Analytical and Bioanalytical Chemistry, vol. 410, no. 2, pp. 349-359, 2018.

[15] D.-D. Zhong, Y.-P. Huang, X.-L. Xin, Z.-S. Liu, and H. A. Aisa, "Preparation of Metallic pivot-based imprinted monolith for polar template," Journal of Chromatography B, vol. 934, pp. 109-116, 2013.

[16] J. Feng, F. Li, R.-X. Ran, Y.-P. Huang, and Z.-S. Liu, "Synergistic effect of metal ions pivot and Macromolecular Crowding reagents on Affinity of molecularly imprinted polymer," European Polymer Journal, vol. 120, Article ID 109242, 2019.

[17] Z.-H. Wei, X. Sun, L.-N. Mu, Y.-P. Huang, and Z.-S. Liu, "Improving Affinity of imprinted monolithic polymer prepared in Deep Eutectic solvent by Metallic pivot," Journal of Chromatography A, vol. 1602, pp. 48-55, 2019.

[18] P. W. Atkins, T. L. Overton, J. P. Rourke, M. T. Weller, F. A. Armstrong, and M. Hagerman, Shriver and Atkins'
Inorganic Chemistry, Oxford University Press, Great Britain, 5 edition, 2010.

[19] W. Ma, Y. An, and K. H. Row, "Preparation and evaluation of a green solvent-based molecularly imprinted monolithic column for the recognition of Proteins by high-performance liquid chromatography," The Analyst, vol. 144, no. 21, pp. 6327-6333, 2019.

[20] A. Gutiérrez-Serpa, P. I. Napolitano-Tabares, J. Šulc, I. Pacheco-Fernández, and V. Pino, "Role of ionic liquids in Composites in Analytical sample preparation," Separations, vol. 7, pp. 1-32, 2020.

[21] T. L. Greaves and C. J. Drummond, "Solvent Nanostructure, the Solvophobic effect and Amphiphile self-assembly in ionic liquids," Chemical Society Reviews, vol. 42, no. 3, pp. 1096-1120, 2013.

[22] X.-Y. Li, X.-X. Chen, D.-D. Zhong, Y.-P. Huang, and Z.-S. Liu, "Synthesis of imprinted monolithic column with high content of monomers in ionic liquid," RSC Advances, vol. 4, no. 92, pp. 50662-50667, 2014.

[23] H. Liu, P. Jin, F. Zhu, L. Nie, and H. Qiu, "A Review on the Use of ionic liquids in preparation of molecularly imprinted polymers for applications in Solid-phase extraction," TRAC Trends in Analytical Chemistry, vol. 134, Article ID 116132, 2021.

[24] A. N. Tasfiyati, E. D. Iftitah, S. P. Sakti, and A. Sabarudin, "Evaluation of Glycidyl methacrylate-based monolith functionalized with weak anion Exchange Moiety inside $0.5 \mathrm{~mm}$ i.d. Column for liquid chromatographic separation of DNA," Analytical Chemistry Research, vol. 7, pp. 9-16, 2016.

[25] S. Amalia, S. C. Angga, E. D. Iftitah et al., "Immobilization of Trypsin onto porous methacrylate-based monolith for flowthrough Protein Digestion and its Potential application to chiral separation using liquid chromatography," Heliyon, vol. 7, no. 8, Article ID e07707, 2021.

[26] S. C. Angga, D. Septiana, S. Amalia, E. D. Iftitah, and A. Sabarudin, "Preparation of poly-(GMA-EDA- $\beta$-CD-coTMPTMA) monolith as high-performance liquid chromatography chiral stationary phase column," Indones. J. Chem.vol. 19, pp. 951-958, 2019.

[27] S. F. Raeni, I. Allwicher, E. D. Iftitah, and A. Sabarudin, "Development of Ti4+-immobilized Nanoporous monolithic polymer for selective separation and detection of Phosphopeptides," Rasayan J. Chem.vol. 11, pp. 345-354, 2018.

[28] Y. Lin, J. Guo, H. Lin et al., "Effect of fabrication strategy on the enantioseparation performance of $\beta$-cyclodextrin-functionalized polymethacrylate monoliths: a comparative evaluation," Journal of Separation Science, vol. 40, no. 19, pp. 3754-3762, 2017.

[29] S. Shu, H. Kobayashi, N. Kojima, A. Sabarudin, and T. Umemura, "Preparation and characterization of lauryl methacrylate-based monolithic microbore column for reversed-phase liquid chromatography," Journal of Chromatography A, vol. 1218, no. 31, pp. 5228-5234, 2011.

[30] J. Zhang, F. Li, X.-H. Wang, D. Xu, Y.-P. Huang, and Z.-S. Liu, "Preparation and characterization of Dual-template molecularly imprinted monolith with metal ion as pivot," European Polymer Journal, vol. 80, pp. 134-144, 2016.

[31] S. Kumar, E. Alveroğlu, A. Balouch et al., "Fabrication of Chromium-imprinted polymer: a real Magneto-Selective Sorbent for the removal of $\mathrm{Cr}(\mathrm{VI})$ ions in real water samples," New Journal of Chemistry, vol. 44, no. 43, pp. 18668-18678, 2020.

[32] S. A. Zaidi and W. J. Cheong, "Preparation of an Open-Tubular capillary column with a monolithic Layer of 
S-Ketoprofen imprinted and 4-Styrenesulfonic acid Incorporated polymer and its Enhanced chiral separation performance in capillary Electrochromatography," Journal of Chromatography A, vol. 1216, no. 14, pp. 2947-2952, 2009.

[33] S. Li, C. Liao, W. Li, Y. Chen, and X. Hao, "Rationally designing molecularly imprinted polymer towards predetermined high selectivity by using metal as assembled pivot," Macromolecular Bioscience, vol. 7, no. 9-10, pp. 1112-1120, 2007.

[34] G. Socrates, Infrared Characteristic Group Frequencies, John Wiley \& Sons, England, 2 edition, 1994.

[35] N. F. Yusof, F. S. Mehamod, and F. B. Mohd Suah, "Fabrication and binding characterization of ion imprinted polymers for highly selective Co2+ ions in an Aqueous Medium," Journal of Environmental Chemical Engineering, vol. 7, no. 2, Article ID 103007, 2019.

[36] X. Zhang, J. Yang, C. Wang et al., "Improving imprinting effect by reducing sites embedding: Selective extraction of 1,2,3,4,6-penta-O-galloyl- $\beta$-d-glucose from Paeonia lactiflora Pall by hydrophilic molecularly imprinted polymers based on macromonomer and metal ion pivot," Microchemical Journal, vol. 158, Article ID 105140, 2020.

[37] S. Shu, H. Kobayashi, M. Okubo, A. Sabarudin, M. Butsugan, and T. Umemura, "Chemical anchoring of lauryl methacrylate-based reversed phase monolith to $1 / 16^{\prime \prime}$ o.d. polyetheretherketone tubing," Journal of Chromatography A, vol. 1242, pp. 59-66, 2012.

[38] H. Yan and K. Row, "Characteristic and Synthetic Approach of molecularly imprinted polymer," International Journal of Molecular Sciences, vol. 7, no. 5, pp. 155-178, 2006.

[39] S. Shoravi, G. Olsson, B. Karlsson, and I. Nicholls, "On the influence of crosslinker on template Complexation in molecularly imprinted polymers: a Computational study of Prepolymerization mixture Events with Correlations to template-polymer recognition Behavior and NMR Spectroscopic studies," International Journal of Molecular Sciences, vol. 15, no. 6, pp. 10622-10634, 2014.

[40] S. Yang, Y. Wang, Y. Jiang, S. Li, and W. Liu, "Molecularly imprinted polymers for the identification and separation of chiral Drugs and Biomolecules," Polymers, vol. 8, pp. 1-16, 2016. 